\title{
Article \\ Plasma Based Protein Signatures Associated with Small Cell Lung Cancer
}

\author{
Johannes F. Fahrmann ${ }^{1,+}{ }^{,}$Hiroyuki Katayama ${ }^{1,+}{ }^{\mathbb{D}}$, Ehsan Irajizad ${ }^{1,+}$, Ashish Chakraborty ${ }^{1}{ }^{\mathbb{D}}$, Taketo Kato ${ }^{1} \mathbb{C}^{\mathbb{D}}$, \\ Xiangying Mao ${ }^{1}{ }^{\oplus}$, Soyoung Park ${ }^{1}$, Eunice Murage ${ }^{1}$, Leona Rusling ${ }^{1}$, Chuan-Yih Yu ${ }^{1}$, Yinging Cai ${ }^{1}$, \\ Fu Chung Hsiao ${ }^{1}$, Jennifer B. Dennison ${ }^{1}$, Hai Tran ${ }^{2}$, Edwin Ostrin ${ }^{3}{ }^{1}$, David O. Wilson ${ }^{4}$, Jian-Min Yuan ${ }^{5,6}$, \\ Jody Vykoukal ${ }^{1}$ and Samir Hanash ${ }^{1, *}$
}

1 Department of Clinical Cancer Prevention, The University of Texas M. D. Anderson Cancer Center, Houston, TX 77030, USA; jffahrmann@mdanderson.org (J.F.F.); HKatayama1@mdanderson.org (H.K.); EIrajizad@mdanderson.org (E.I.); ashishchak@utexas.edu (A.C.); TKato1@mdanderson.org (T.K.); XMao2@mdanderson.org (X.M.); SNPark@mdanderson.org (S.P.); ENMurage@mdanderson.org (E.M.); LAMartin1@mdanderson.org (L.R.); CYu3@mdanderson.org (C.-Y.Y.); YCai4@mdanderson.org (Y.C.); FCHsiao@mdanderson.org (F.C.H.); jbdennis@mdanderson.org (J.B.D.); jvykouka@mdanderson.org (J.V.)

2 Department of Thoracic-Head \& Neck Medical Oncology, The University of Texas M. D. Anderson Cancer Center, Houston, TX 77030, USA; htran@mdanderson.org

3 Department of Pulmonary Medicine, The University of Texas M. D. Anderson Cancer Center, Houston, TX 77030, USA; EJOstrin@mdanderson.org

4 Division of Pulmonary, Allergy and Critical Care Medicine, School of Medicine, University of Pittsburgh, Pittsburgh, PA 15213, USA; wilsondo@upmc.edu

5 Division of Cancer Control and Population Sciences, UPMC Hillman Cancer Center, University of Pittsburgh, Pittsburgh, PA 15232, USA; yuanj@upmc.edu

check for updates

Citation: Fahrmann, J.F.; Katayama, H.; Irajizad, E.; Chakraborty, A.; Kato, T.; Mao, X.; Park, S.; Murage, E.; Rusling, L.; Yu, C.-Y.; et al. Plasma Based Protein Signatures Associated with Small Cell Lung Cancer. Cancers 2021, 13, 3972. https://doi.org/ $10.3390 /$ cancers13163972

Academic Editor: Federico Cappuzzo

Received: 15 June 2021

Accepted: 4 August 2021

Published: 6 August 2021

Publisher's Note: MDPI stays neutral with regard to jurisdictional claims in published maps and institutional affiliations.

Copyright: (c) 2021 by the authors. Licensee MDPI, Basel, Switzerland. This article is an open access article distributed under the terms and conditions of the Creative Commons Attribution (CC BY) license (https:// creativecommons.org/licenses/by/ $4.0 /)$.
6 Department of Epidemiology, Graduate School of Public Health, University of Pittsburgh, Pittsburgh, PA 15261, USA

* Correspondence: shanash@mdanderson.org

$\dagger$ These authors contributed equally to this work.

Simple Summary: Small-cell lung cancer (SCLC) typically presents at an advanced stage and is associated with high mortality. When diagnosed at an early stage with localized disease, long-term survival can, however, be achieved. In this study, we report a comprehensive proteomic profiling of case plasmas collected at the time of diagnosis or preceding diagnosis of SCLC with the objective of identifying blood-based markers associated with disease pathogenesis. Our study reveals the occurrence of circulating protein features centered on signatures of oncogenic MYC and YAP1 that were elevated in plasmas of cases at and before the time-of-diagnosis of SCLC. We further report several proteins, particularly inflammatory markers, that were identified as elevated in plasma several years prior to the diagnosis of SCLC and that may indicate increased risk of disease. In summary, our study identifies several novel circulating proteins associated with SCLC development that may offer utility for early detection.

Abstract: Small-cell-lung cancer (SCLC) is associated with overexpression of oncogenes including Myc family genes and YAP1 and inactivation of tumor suppressor genes. We performed in-depth proteomic profiling of plasmas collected from 15 individuals with newly diagnosed early stage SCLC and from 15 individuals before the diagnosis of SCLC and compared findings with plasma proteomic profiles of 30 matched controls to determine the occurrence of signatures that reflect disease pathogenesis. A total of 272 proteins were elevated (area under the receiver operating characteristic curve $(A U C) \geq 0.60$ ) among newly diagnosed cases compared to matched controls of which 31 proteins were also elevated (AUC $\geq 0.60$ ) in case plasmas collected within one year prior to diagnosis. Ingenuity Pathway analyses of SCLC-associated proteins revealed enrichment of signatures of oncogenic MYC and YAP1. Intersection of proteins elevated in case plasmas with proteomic profiles of conditioned medium from 17 SCLC cell lines yielded 52 overlapping proteins characterized by YAP1-associated signatures of cytoskeletal re-arrangement and epithelial-to-mesenchymal transition. Among samples collected more than one year prior to diagnosis there was a predominance of inflam- 
matory markers. Our integrated analyses identified novel circulating protein features in early stage SCLC associated with oncogenic drivers.

Keywords: small-cell lung cancer; proteomics; biomarkers

\section{Introduction}

Small-cell lung cancer (SCLC) is a highly lethal malignancy that generally presents at an advanced stage and is associated with neuroendocrine phenotypic features $[1,2]$. When diagnosed at an early stage with localized disease, long-term survival can be achieved [3].

The National Lung Cancer Screening Trial (NLST) findings indicate screening with LDCT can reduce mortality due to lung cancer by $20 \%$, with similar results since reported from the NELSON trial [4,5].Yet, CT-based screening in NLST was not found effective for detecting small-cell lung cancer (SCLC) at an early stage, with SCLC often being detected as an interval cancer [6], without a survival improvement amongst these subjects [7]. Thus, there remains a clinical need to develop biomarkers to enable detection of SCLC at an early stage to improve the potential for longer survival.

Increasing evidence highlights utility of liquid-biopsies as an ideal 'minimally invasive' approach for early interception of disease by identifying of those individuals who are at high risk of either developing or harboring disease and thereby triggering clinical follow-up such as LDCT [8-11]. In prior studies of lung adenocarcinoma, we identified a circulating protein signature that reflected activation at early stages of Titf1/Nkx2-1, a known lineagesurvival oncogene in lung cancer. The signature notably included the immature form of surfactant protein B [12]. Subsequent validation studies provided evidence that a biomarker panel including prosurfactant protein B may improve lung cancer risk assessment [8]. However, there remains a need to uncover biomarker signatures that reflect subtypes of lung cancer at early stages. To date, several blood-based markers have been identified in association with SCLC, including neuron specific enolase (NSE), Progastrin-releasing peptide (ProGRP), chromogranin A (CgA) and pro-opiomelanocortin (POMC) [13-19]. Performance of these markers in the early stage setting is limited because of reduced expression $[14,16,17]$.

Molecular characterization of tumor tissues has identified key determinants associated with SCLC development and progression including loss of TP53 and RB1, MYC copy number amplification, and activation of the PI3K/AKT/mTOR pathway [20-23]. More recent evidence has defined a new classification model of SCLC subtypes, characterized by differential expression of the transcriptional regulators achaete-scute homologue 1 (ASCL1), neurogenic differentiation factor 1 (NeuroD1), yes-associated protein 1 (YAP1) and POU class 2 homeobox 3 (POU2F3) [24].

In this study, we performed comprehensive proteome profiling of plasmas collected before the diagnosis of SCLC and plasmas from subjects with newly diagnosed early stage SCLC and compared findings to proteomic profiles from matched healthy controls to assess the potential association of protein changes in circulation with oncogenic drivers in SCLC. Findings were further integrated with proteomic profiles of conditioned media from 17 SCLC cell lines and gene expression data from SCLC tumors.

\section{Materials and Methods}

\subsection{Human Specimen}

All human blood samples were obtained following institutional review board approval, and patients provided written informed consent.

The initial discovery set consisted of EDTA-plasma samples from 15 newly diagnosed early stage SCLC cases and 15 controls matched on sex, age and smoking history from the University of Texas MD Anderson Cancer Center (MDACC) (Table 1). Case plasmas were obtained from participants in the Genomic Marker-Guided Therapy Initiative (GEM- 
INI) project (IRB protocol PA13-0589). The GEMINI project entails detailed clinical and molecular information of over 4000 lung cancer patients as well as a biorepository for plasma samples. Control plasmas were selected from participants in the Lung cancer Early Detection Assessment of risk, and Prevention (LEAP) study (IRB protocol 2013-0609). The LEAP cohort includes 586 participants enrolled at MD Anderson who were eligible for low-dose CT screening based on United States Preventative Services Task Force (USPSTF) 2013 criteria. Control plasmas were selected from participants that were confirmed to be cancer-free for a minimum of four years following blood draw.

Table 1. Patient and tumor characteristics for MDACC Cohort.

\begin{tabular}{lccc}
\hline \multicolumn{1}{c}{ Patient and Tumor Characteristics } & Cases & Controls & $p^{\dagger}$ \\
\hline$N$ & 15 & 15 & \\
Age, mean \pm stdev & $67 \pm 10$ & $64 \pm 5$ & 0.330 \\
Sex, $N(\%)$ & & & \\
$\quad$ Male & $8(53.3 \%)$ & $8(53.3 \%)$ & \\
$\quad$ Female & $7(46.7 \%)$ & $7(46.7 \%)$ & \\
Stage, $N(\%)$ & $6(40 \%)$ & - & \\
$\quad$ I & $9(60 \%)$ & - & 0.200 \\
$\quad$ II & $63 \pm 27$ & $51 \pm 18$ & \\
Smoking PYs, mean \pm stdev &
\end{tabular}

${ }^{\dagger}$ 2-sided student $t$-test.

The pre-clinical cohort consisted of pre-diagnostic plasmas from 15 SCLC subjects diagnosed within a median of 2.4 years of blood draw along with 15 controls with no history of cancer during the period of follow-up. Samples were derived from participants in the Pittsburgh Lung Screening Study (PLuSS) [25] and Singapore Chinese Health Study (SCHS) [26]. Controls were matched based on age, sex and smoking status (Table 2).

Table 2. Patient and tumor characteristics for the entire pre-diagnostic SCLC Cohort.

\begin{tabular}{lcc}
\hline \multicolumn{1}{c}{ Patient and Tumor Characteristics } & Cases & Controls \\
\hline$N$ & 15 & 15 \\
Age, mean \pm stdev & $62.6 \pm 8.7$ & $62.5 \pm 8.9$ \\
Years from Dx, median (min/max) & $2.4(0.7,12.3)$ & - \\
Sex, $N(\%)$ & & \\
Female & $8(53.3 \%)$ & $8(53.3 \%)$ \\
Male & $7(46.7 \%)$ & $7(46.7 \%)$ \\
Smoking Status, $N(\%)$ & $2(13.3 \%)$ & $2(13.3 \%)$ \\
$\quad$ Former & $12(80.0 \%)$ & $12(80.0 \%)$ \\
$\quad$ Current & $1(6.7 \%)$ & $1(6.7 \%)$ \\
Never & & \\
\hline
\end{tabular}

The PLuSS cohort recruiting criteria were: (1) age 50 to 79 years; (2) no personal lung cancer history; (3) nonparticipation in concurrent lung cancer screening studies; (4) no chest computed tomography (CT) within 12 months; (5) current or ex-cigarette smoker of at least one-half pack per day for at least 25 years, and, if they quit smoking, quit for no more than 10 years before study enrollment; and (6) body weight less than 400 pounds from January 2002 [25].

The SCHS enrolled a total of 63,257 Chinese persons aged 45-74 years between 1993 and 1998. Participants belonged to one of the major dialect groups (Hokkien or Cantonese) of Chinese in Singapore and were citizens or permanent residents of government-built housing estates, where $86 \%$ of the general population resided during the enrollment period. Cancer diagnoses and deaths in this cohort were identified via linkage with the Singapore Cancer Registry and the Singapore Registry of Births and Deaths [26]. 


\subsection{SCLC Cell Line-Derived Conditioned Media}

Seventeen SCLC cell lines (H1607, HCC4002, H209, H211, H2195, H2679, H345, H524, H526, H69P, H69AD, H82, HCC4001, HCC4003, HCC4004, HCC4005, H1048) representative of the consensus SCLC subtypes were analyzed (Appendix A Table A1) [24].

Collection of conditioned media for protein analysis was performed as previously described [12]. Briefly, SCLC cell lines were grown in RPMI1640 (Pierce) containing 10\% of dialyzed fetal bovine serum (FBS) (Invitrogen), 1\% penicillin/streptomycin cocktail and 13C-lysine (Cambridge Isotope Laboratories, \#CLM-2247-H) for 7 passages in accordance with the standard SILAC protocol [27]. The purpose of 13C-lysine labeling was to enable discrimination between SCLC released proteins and proteins that occur in FBS. Whole cell extracts of cells were prepared by sonication of $\sim 2 \times 10^{7}$ cells in $1 \mathrm{~mL}$ of Tri- $\mathrm{HCl}$ buffer ( $\mathrm{pH}$ 8.0) containing detergent octyl-glucoside (OG) $(1 \% w / w), 4 \mathrm{M}$ urea, $3 \%$ isopropanol and protease inhibitors (complete protease inhibitor cocktail, Roche Diagnostics, Germany) followed by centrifugation at $20,000 \times g$. Secreted and shed proteins were obtained directly from the cell conditioned media with $0.1 \%$ dialyzed FBS after $48 \mathrm{~h}$ of culture. Cells and debris were removed by centrifugation at $5000 \times g$ and filtration through a $0.22 \mu \mathrm{m}$ filter.

\subsection{Mass Spectrometry Analyses of Human Plasmas}

Plasma volumes of $100 \mu \mathrm{L}$ were processed using immuno-depletion affinity column Hu-14 $10 \times 100$ mm (Agilent Technologies, Santa Clara, CA USA, \#5188-6559) to remove 14 high abundance plasma proteins: Albumin, IgG, IgA, Transferrin, Haptoglobin, Fibrinogen, $\alpha 1$-Antitrypsin, $\alpha 1$-Acid Glycoprotein, Apolipoprotein AI, Apolipoprotein AII, Complement C3, Transthyretin, IgM and $\alpha 2$-Marcroglobulin. The flow-through fraction was then used for profiling the lower abundance free (non-Ig bound) plasma proteome. To prepare for proteomics analysis, samples were concentrated and reduced with TCEP and alkylated by 2-chloro-N,N-diehtylcarbamidomethyl (diethylcarbamidomethyl). Next, the buffer was exchanged to TEAB and trypsin digested, $100 \mu \mathrm{g}$ corresponding peptides from each pool was desalted by C18-CX Monospin column (GL Sciences, Torrance, CA, USA) and dried by SpeedVac (Thermo Scientific, Waltham, MA, USA). Each of the dried pool was individually dissolved and labeled with 10 plex Lys-TMT Channel (Thermo Scientific, \#90309) and combined, fractionated into 12 fractions with alkaline $0.1 \%$ Triethylamine/acetonitrile reversed phase mode using C18 Monospin Large column (GL Sciences, Torrance, CA, USA). The step elution was done by B concentration of $20 \%, 25 \%, 30 \%, 35 \%$, $40 \%, 45 \%, 50 \%, 55 \%, 60 \%, 70 \%, 80 \%$ and $100 \%$ using mobile phase A $(0.1 \%$ Triethylamine in Water/acetonitrile $98 / 2)$ and Mobile phase B (0.1\% Triethylamine in water/acetonitrile $5 / 95)$, then the fractions were dried by the SpeedVac (Thermo Scientific).

The samples were subsequently reconstituted with acetonitrile/water/trifluoroacetic acid (TFA) (2:98:0.1, v/v/v) and individually analyzed by Easy nanoLC 1000 system (Thermo Scientific, Waltham, MA, USA) coupled Q-exactive mass spectrometer using a $15 \mathrm{~cm}$ column (75 $\mu \mathrm{m}$ ID, C18 $3 \mu \mathrm{m}$, column Technology Inc) as a separation column, and Symmetry C18 180 um ID $\times 20 \mathrm{~mm}$ trap column (Waters Inc., Milford, MA, USA) over a 120 min gradient. Mass spectrometer parameters were spray voltage $3.0 \mathrm{kV}$, capillary temperature $275^{\circ} \mathrm{C}$, Full scan MS of scan range 350-1800 m/z, Resolution 70,000, AGC target 3e6, Maximum It $50 \mathrm{msec}$ and Data dependent MS2 scan of resolution 17,500 in profile mode, AGC target 1e5, Maximum IT $100 \mathrm{msec}$ and repeat count 10 in HCD mode.

Acquired mass spectrometry data were processed by Proteome Discover 1.4 (Thermo Scientific). The tandem mass spectra were searched against Uniprot human database 2017 using Sequest HT. The modification parameters were as follows: fixed modification of Cys alkylated with diethylcarbamidomethyl (+113.084064), Lys with 10 plex TMT $(+229.162932$, $\mathrm{N}$-terminal and Lys), and variable modification of Methionine oxidation (+15.99491). The precursor mass tolerance of the parent and fragment mass were $10 \mathrm{ppm}$ and $0.02 \mathrm{Da}$, respectively. Searched data was further processed with the Target Decoy PSM Validator function with a false-discovery rate (FDR) of 0.05 . 


\subsection{Mass Spectrometry Analyses of SCLC Cell Line Conditioned Media}

SCLC cell line conditioned media were concentrated and reduced with TCEP and alkylated by acrylamide (propionamide) and the intact proteins were fractionated into 14 fractions by AQUITY UPLC system (Waters Inc., Milford, MA, USA) in reversed phase mode using a RPGS reversed-phase column $(4.6 \mathrm{~mm} \times 150 \mathrm{~mm}, 15 \mu \mathrm{m}$ particle, $1000 \AA$, Column Technology Inc, Fremont, CA, USA) and dried, trypsin digested and subjected to mass spectrometry analysis. The tryptic peptides were analyzed by NanoAcquity UPLC system coupled to WATERS SYNAPT G2-Si mass spectrometer using $15 \mathrm{~cm}$ column $(75 \mu \mathrm{m}$ ID, C18 3um, Column Technology Inc, Fremont, CA, USA) as a separation column, and Symmetry C18 $180 \mu \mathrm{m}$ ID $\times 20 \mathrm{~mm}$ trap column (Waters Inc., Milford, MA, USA) over a 120 min gradient. LC HDMSE data were acquired in resolution mode with SYNAPT G2-Si using Waters Masslynx (version 4.1, SCN 851, Waters Inc). The capillary voltage was set to $2.80 \mathrm{kV}$, sampling cone voltage to $30 \mathrm{~V}$, source offset to $30 \mathrm{~V}$ and source temperature to $100{ }^{\circ} \mathrm{C}$. Mobility utilized high-purity N2 as the drift gas in the IMS TriWave cell. Pressures in the helium cell, Trap cell, IMS TriWave cell and Transfer cell were 4.50 mbar, $2.47 \times 10^{-2}$ mbar, 2.90 mbar and $2.53 \times 10^{-3}$ mbar, respectively. IMS wave velocity was $600 \mathrm{~m} / \mathrm{s}$, helium cell DC $50 \mathrm{~V}$, Trap DC bias $45 \mathrm{~V}$, IMS TriWave DC bias V and IMS wave delay $1000 \mu \mathrm{s}$. The mass spectrometer was operated in V-mode with a typical resolving power of at least 20,000. All analyses were performed using positive mode ESI using a NanoLockSpray source. The lock mass channel was sampled every $60 \mathrm{~s}$. The mass spectrometer was calibrated with a (Glu1) fibrinopeptide solution $(300 \mathrm{fmol} / \mu \mathrm{L})$ delivered through the reference sprayer of the NanoLockSpray source. Accurate mass LC-HDMSE data were collected in an alternating, low energy (MS) and high energy (MSE) mode of acquisition with mass scan range from $\mathrm{m} / \mathrm{z} 50$ to 1800 . The spectral acquisition time in each mode was $1.0 \mathrm{~s}$ with a 0.1-s inter-scan delay. In low energy HDMS mode, data were collected at a constant collision energy of $2 \mathrm{eV}$ in both Trap cell and Transfer cell. In high energy HDMSE mode, the collision energy was ramped from 25 to $55 \mathrm{eV}$ in the Transfer cell only. The RF applied to the quadrupole mass analyzer was adjusted such that ions from $\mathrm{m} / \mathrm{z} 300$ to 2000 were efficiently transmitted, ensuring that any ions observed in the LC-HDMSE data less than $\mathrm{m} / \mathrm{z}$ arose from dissociations in the Transfer collision cell. The acquired LC-HDMSE data was subsequently processed and searched against the Uniprot proteome database (Human, January 2017) through the ProteinLynx Global Server (PLGS, Waters Inc., Milford, MA, USA) with two trypsin miss cleavage allowed. The modification search settings included cysteine (Cys) alkylation with propionamide $(+71.03714)$ as a fixed modification, and methionine (Met) oxidation $(+15.99491)$ as a variable modification. The searched data was filtered with a False Discovery Rate $4 \%$.

The total number of spectral counts for each protein group output was used for semiquantitative analyses. Each dataset was normalized to the total number of spectral counts. To mitigate potential bias of proteins manifest in conditioned media as a result of cell turnover, we employed the spectral counting method to estimate protein enrichment in conditioned media as previously described [12]. Briefly, enrichment in conditioned media was calculated as follows: $\left[\left(C_{x p} / N f\right)+1\right] /\left(C_{\text {te }} p+1\right)$. $C_{x}$ represents spectral counts of each protein $(\mathrm{p})$ in the conditioned media; $\mathrm{Nf}$ is the normalization factor (total spectral counts in the conditioned media/total spectral counts in the whole extract); Cte is the spectral counts for the same protein $(p)$ observed in the whole cell extract. Here, we considered a protein to be enriched in SCLC cell line conditioned medium if the enrichment ratio $\geq 2$.0.

\subsection{Ingenuity Pathway Enrichment Analysis}

Ingenuity Pathway Enrichment Analysis (IPA) [28] was conducted on proteins identified by mass spectrometry that were elevated in plasmas of patients that later developed SCLC or in plasmas of patients with newly diagnosed early stage SCLC as well as proteins that were elevated in case plasmas and that were also quantified in SCLC cell line conditioned media. Statistical significance of enriched pathways was determined by 2-sided Fisher's Exact Test. Subcellular localization as well as functional subtyping of protein fea- 
tures were derived from IPA; proteins annotated as being secreted was downloaded from The Human Protein Atlas (https:/ / www.proteinatlas.org/humanproteome/ cell/secreted+ proteins, accessed on the 3 March 2021). ChIP Enrichment Analysis (ChEA) transcriptional targets of c-MYC and YAP1 were downloaded from Harmonizome database [29,30]. For MYC, we utilized the MYC-20876797 Human Medulloblastoma gene set.

\subsection{Statistical Analysis}

For human plasmas, model discrimination was assessed by area under curve (AUC) of the receiver operating characteristic curve (ROC). ROC analyses were performed using pROC (version 1.15.3) in the R software environment (version 3.6.1, The R Foundation). The 95\% confidence intervals (CI) for AUCs were estimated using Delong method [31]. $p$-values are reported based on 2-sided Wilcoxon rank sum test unless otherwise specified. We chose to focus on AUC to evaluate the distribution of data points and to assess the ability of features to distinguish cases from controls. Herein, we selected those markers that were elevated in cases using a cutoff of AUC greater than 0.60. Odds ratio was used to assess the performance for pre-diagnosis cases where their respective diagnosis time are more than 1 year. Markers with odds ratio greater and equal to 2 was selected as important markers.

\section{Results}

3.1. Proteomic Profiling Reveals Signatures Associated with Oncogenic Drivers Manifest in Plasmas at Early Stages of SCLC

To identify plasma-based signatures for early stage SCLC, we performed comprehensive proteomic profiling of individual plasmas collected from 15 newly diagnosed early stage SCLC cases (6 stage I and 9 stage II) and 15 controls matched based on age, sex and smoking pack years (Table 1). Using a threshold of identification in at least 50\% of the samples, a total of 1587 plasma proteins were quantified. Differential analyses yielded 272 proteins with AUC estimates of $\geq 0.60$ for differentiating SCLC cases from matched controls, which included the SCLC-associated marker ENO2/NSE (Figure 1A and Supplemental Dataset S1) [14,16,19]

Ingenuity pathway analysis (IPA) of the 272 proteins revealed YAP1 and related transcriptional enhanced associate domain transcription factor (TEAD)-family members [32] among top predicted transcriptional regulators, in addition to MYC as a central network node (Figure 1B,C). To this end, intersection of protein findings with ChEA transcriptional targets of MYC and YAP1 revealed 15 of the 272 proteins to be known transcriptional targets of c-MYC whereas another $49(18.0 \%)$ are known transcriptional targets of YAP1 (Supplemental Dataset S1).

Among the 15 MYC-associated proteins were several proteins involved in epithelialto-mesenchymal transition (EMT), including CIT, DIAPH3, FBXO11, THBS1 and YWHAZ (Appendix A Table A2). YAP1-associated proteins were biologically linked to actin cytoskeletal signaling and epithelial adherens junction signaling (Appendix A Table A3) [33,34]. Moreover, several cytoskeletal associated-proteins including ACTB, ATCBL2, ACTC1, COTL1, FERMT3, PFN1, TPM3, TPM4 and VCL were found to be elevated in case plasmas compared to matched control (Supplemental Dataset S1), that may reflect cytoskeletal reorganization and degradation of the extracellular matrix $(\mathrm{ECM})$ that occurs during EMT [35-37]. 
A

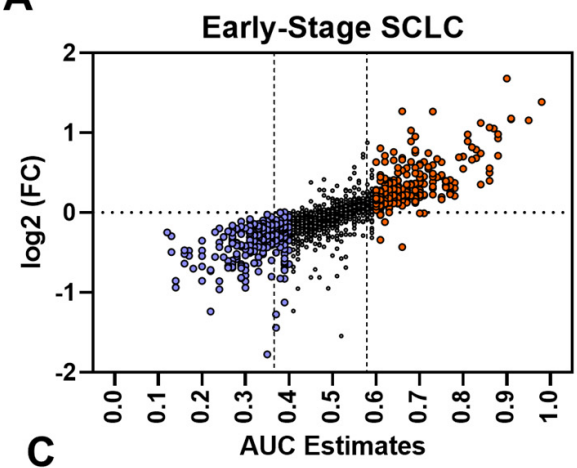

C

\begin{tabular}{cc}
\hline \multicolumn{2}{c}{ Predicted Upstream Transcriptional Regulators } \\
\hline Upstream Regulator & P-value \\
MYC & $4.75 \times 10^{-2}$ \\
YAP1 & $2.01 \times 10^{-2}$ \\
TEAD1 & $4.23 \times 10^{-3}$ \\
TEAD2 & $1.48 \times 10^{-2}$ \\
TEAD3 & $2.47 \times 10^{-3}$ \\
TEAD4 & $2.82 \times 10^{-2}$ \\
\hline
\end{tabular}

B

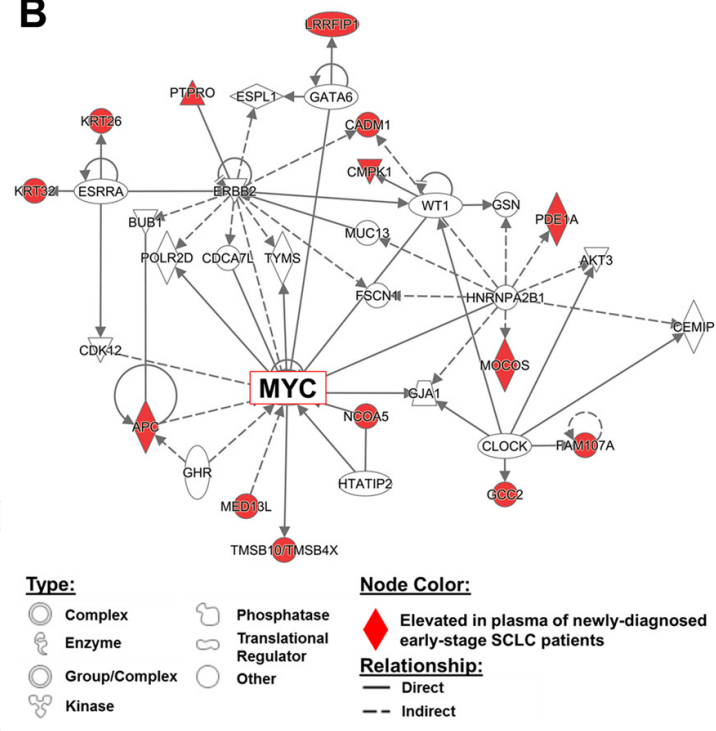

D

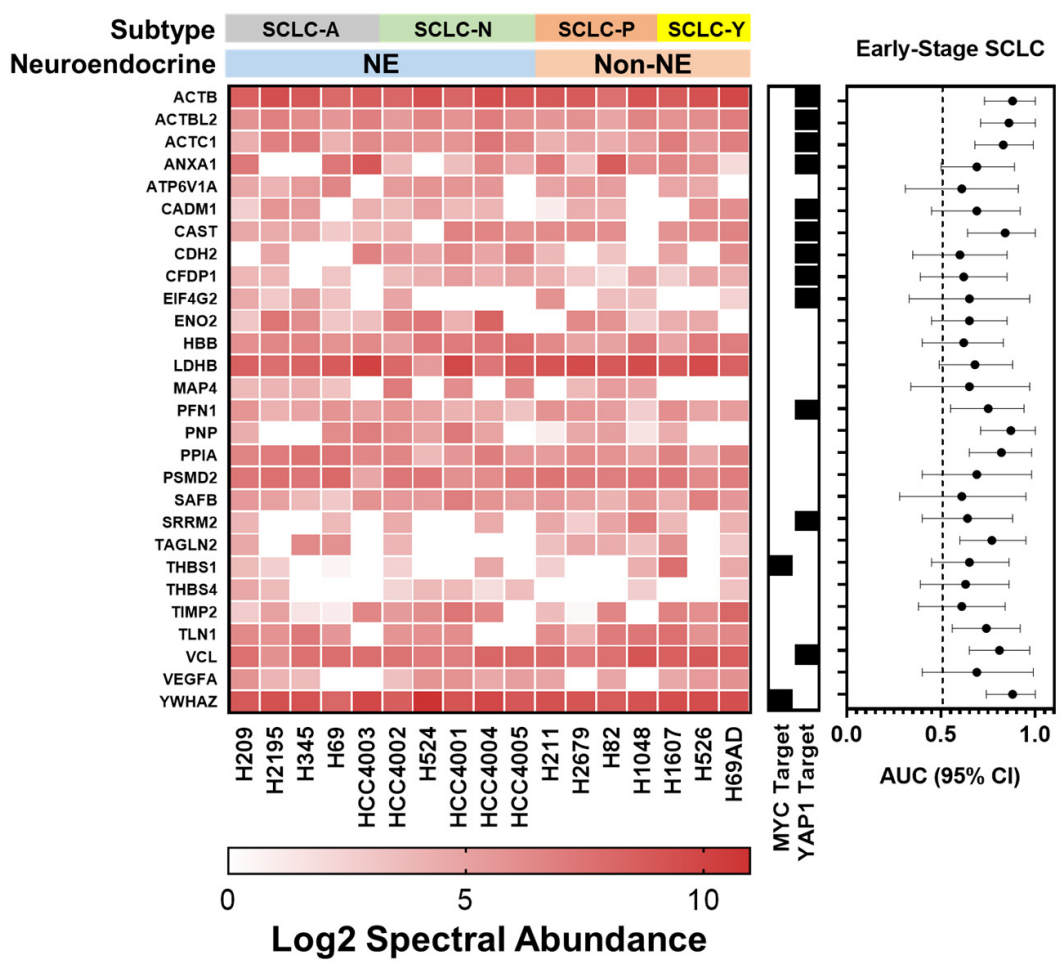

Figure 1. Proteomic profiling of newly diagnosed early stage SCLC patient plasmas reveals signatures associated with oncogenic drivers. (A) Distribution plot comparing illustrating the AUC $(x$-axis) and fold-change ( $y$-axis) of circulating proteins for distinguishing early stage SCLC cases from matched controls. (B,C) Ingenuity Pathway Analyses (IPA) on circulating proteins that exhibited an AUC $\geq 0.60$ for distinguishing early stage SCLC cases from matched controls reveals MYC (B) and YAP1-centric signatures (C). (D) Heatmap illustrating the 28 proteins that were quantified in conditioned medium of SCLC cell lines $(n=17)$ and that were elevated in plasmas of early stage SCLC cases. The center plot annotates whether the respective protein is a reported downstream transcriptional target (black square) of MYC or YAP1. ChIP Enrichment Analysis (ChEA) transcriptional targets of c-MYC and YAP1 were downloaded from Harmonizome database [29,30]. The scatter plot on the right depicts the AUC $(95 \% \mathrm{CI})$ of respective proteins for distinguishing early stage SCLC cases from matched controls in the MDACC cohort. 


\subsection{Intersection of SCLC-Associated Protein Signatures between Human and SCLC Cell Line-Derived Conditioned Medium}

We searched proteins released into conditioned media (CM) of 17 SCLC cell lines to determine the overlap with proteins that were elevated (AUC $\geq 0.60)$ in plasmas of early stage SCLC cases and to assess whether SCLC tumor cells potentially contribute to increased levels of some of these proteins. A total of 641 proteins were quantified in SCLC cell line CM based on a threshold of identification in at least $50 \%$ of the cell lines and an enrichment ratio $>2.0$ (see Section 2) (Supplemental Dataset S2). Of these, 28 overlapped with proteins that were also found to be elevated (AUC $\geq 0.60$ ) in case plasmas (Figure 1D). Of note, among the overlapping proteins were several of the YAP1 transcriptional targets (ACTB, ACTBL2, ACTC1, ANXA1, CADM1, CAST, CDH2, CFDP1, EIF4G2, PFN1, SRRM2 and VCL) as well as MYC transcriptional targets (THBS1 and YWHAZ) (Figure 1D). IPA analyses of the 28 proteins indicated alterations in integrin signaling and actin cytoskeleton signaling among top enriched pathways whereas top predicted molecular functions were related to cellular movement, and cell-to-cell signaling and interaction (Appendix A Table A4), supporting YAP1-associated signatures of cytoskeletal re-arrangement and EMT as prominent features manifest in blood of SCLC cases.

\subsection{Proteomic Signatures in Plasmas Collected within One Year Prior to Diagnosis of SCLC}

We assessed the extent to which proteins identified in plasmas of early stage SCLC cases were similarly manifest in the blood collected within one year prior to diagnosis (Table 2). A total of 1552 plasma proteins were quantified using the same filtering criteria described above (Supplemental Dataset S3).

Among case plasmas collected within one year prior to diagnosis 483 proteins yielded an AUC $\geq 0.60$ compared to controls (Figure 2A and Supplemental Dataset S3). Consistent with our findings with samples collected at the time of diagnosis, IPA analysis of proteins with AUC $\geq 0.60$ yielded MYC [20] as a central network node with 33 proteins representing transcriptional targets of oncogenic MYC which included several proteins (ANKHD1, ANPEP, CDH12, CDH13, CLASP2, EGFL7, FOXP2, IQGAP3, PAX1, PLEKHA1, THBS1, TPM1, TPX2 and YWHAZ) that are associated with epithelial to mesenchymal transition (EMT) (Appendix A Table A2); YAP1-associated TEAD family members were also found among top predicted upstream regulators (Figure 2B,C) with 61 proteins consisting of transcriptional targets of YAP1 of which several are related to epithelial adherens junction signaling and remodeling (Appendix A Table A3).

Of the proteins with AUC $\geq 0.60$ in plasmas of early stage SCLCL cases, 78 were also quantified in the pre-diagnostic specimen set of which 31 were found to be elevated (AUC $\geq 0.60$ ) in plasma of cases diagnosed within one year of blood draw, which included several of YAP1 and MYC-associated proteins (Table 3). Of the proteins that were elevated (AUC $\geq 0.60$ ) in either case plasma sets, there were 52 proteins that were also quantified in SCLC conditioned media (Figures 1D and 2D). Moreover, 9 of the 31 overlapping proteins between the two case sets were quantified in SCLC cell line conditioned medium (Table 3). 

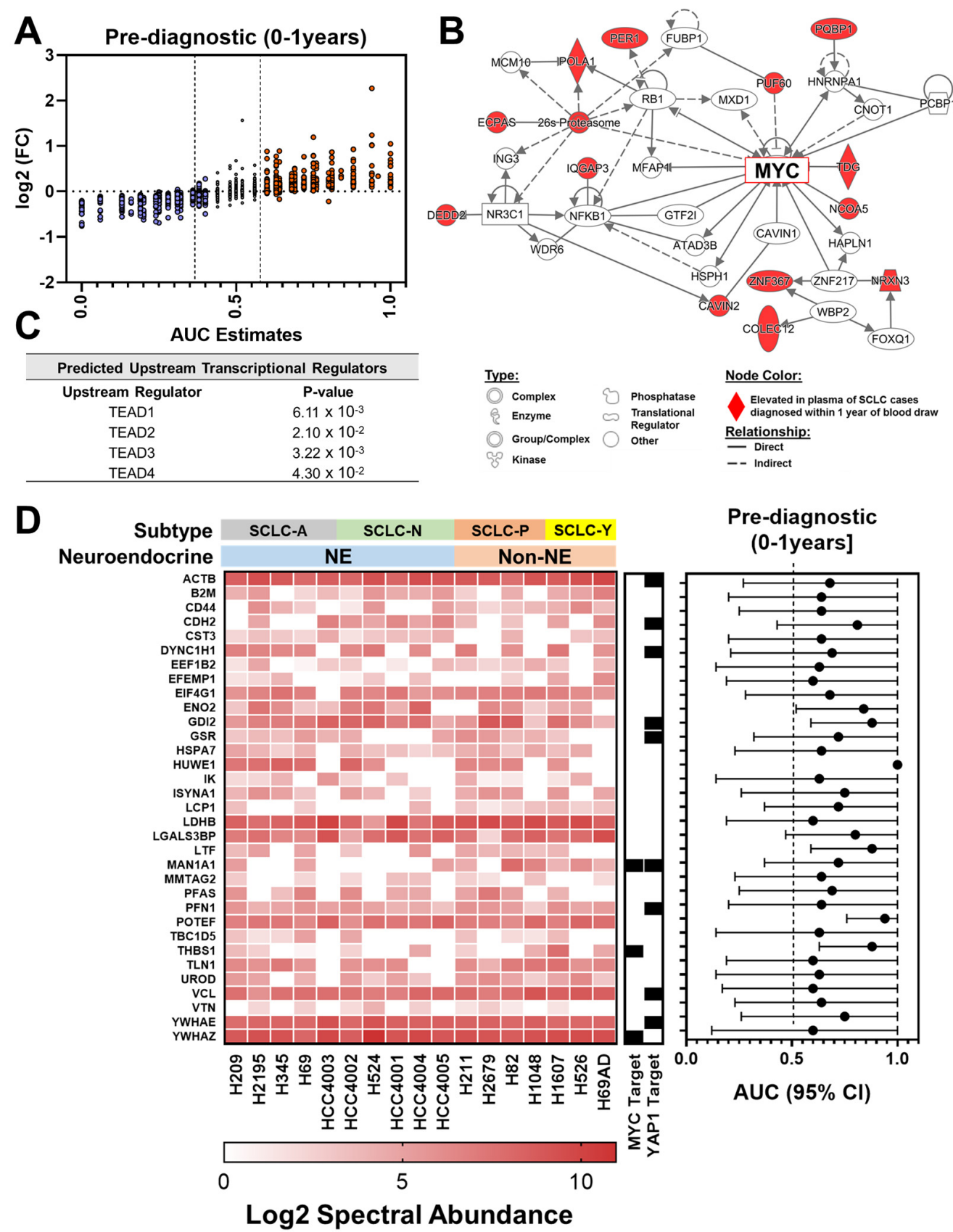

Figure 2. Proteomic signatures of MYC and YAP1 manifest in plasmas collected within one year prior to diagnosis of SCLC. (A) Distribution plot comparing illustrating the AUC ( $x$-axis) and fold-change (y-axis) of circulating proteins for distinguishing SCLC cases diagnosed within one year of blood draw from matched controls. (B,C) Ingenuity Pathway Analyses (IPA) on circulating proteins that exhibited an AUC $\geq 0.60$ for distinguishing SCLC cases diagnosed within one year of blood draw from matched controls reveals MYC (B) and YAP1-centric signatures (C). (D) Heatmap illustrating the 33 proteins that were quantified in conditioned medium of SCLC cell lines $(n=17)$ and that were elevated in plasmas of SCLC cases diagnosed within one year of blood draw. The center plot annotates whether the respective protein is a reported downstream transcriptional target (black square) of MYC or YAP1. ChIP Enrichment Analysis (ChEA) transcriptional targets of c-MYC and YAP1 were downloaded from Harmonizome database $[29,30]$. The scatter plot on the right depicts the AUC $(95 \% \mathrm{CI})$ of respective proteins for distinguishing SCLC cases from matched controls in the pre-diagnostic (0-1 year] dataset. 
Table 3. Overlap of proteins elevated (AUC $\geq 0.60$ ) in case plasmas at the time-of-diagnosis and preceding diagnosis of SCLC.

\begin{tabular}{|c|c|c|c|c|c|}
\hline Protein & $\begin{array}{c}\text { At-Dx } \\
\text { Early Stage SCLC }{ }^{\dagger}\end{array}$ & $\begin{array}{c}\text { Pre-Dx } \\
(0-1 \text { Year }]^{\dagger}\end{array}$ & $\begin{array}{l}\text { Quantified in } \\
\text { SCLC CM } \ddagger\end{array}$ & $\begin{array}{c}\text { MYC Downstream } \\
\text { Target } \|\end{array}$ & $\begin{array}{c}\text { YAP1 Downstream } \\
\text { Target } \|\end{array}$ \\
\hline $\mathrm{ACTB}$ & $0.88(0.73-1.00)$ & $0.68(0.27-1.00)$ & Yes & - & Yes \\
\hline C9 & $0.60(0.38-0.81)$ & $0.60(0.19-1.00)$ & - & - & - \\
\hline CA1 & $0.64(0.43-0.85)$ & $0.60(0.19-1.00)$ & - & - & - \\
\hline CDH2 & $0.60(0.35-0.85)$ & $0.81(0.43-1.00)$ & Yes & - & Yes \\
\hline COL6A6 & $0.61(0.3-0.92)$ & $0.64(0.23-1.00)$ & - & - & - \\
\hline СРТ2 & $0.78(0.52-1.00)$ & $0.64(0.20-1.00)$ & - & - & Yes \\
\hline CRP & $0.68(0.49-0.88)$ & $0.64(0.25-1.00)$ & - & - & - \\
\hline D2HGDH & $0.66(0.46-0.87)$ & $0.63(0.14-1.00)$ & - & - & - \\
\hline ENO2 & $0.65(0.45-0.85)$ & $0.84(0.52-1.00)$ & Yes & - & - \\
\hline KIF27 & $0.64(0.34-0.94)$ & $0.75(0.26-1.00)$ & - & - & - \\
\hline KLHDC10 & $0.62(0.30-0.94)$ & $0.63(0.14-1.00)$ & - & - & Yes \\
\hline LDHB & $0.68(0.49-0.88)$ & $0.60(0.19-1.00)$ & Yes & - & - \\
\hline LONRF1 & $0.86(0.66-1.00)$ & $0.94(0.76-1.00)$ & - & - & - \\
\hline MLPH & $0.75(0.49-1.00)$ & $0.69(0.21-1.00)$ & - & - & - \\
\hline MYD88 & $0.70(0.48-0.92)$ & $0.76(0.41-1.00)$ & - & - & - \\
\hline NCOA5 & $0.63(0.37-0.88)$ & $0.60(0.19-1.00)$ & - & - & - \\
\hline OLFML2A & $0.66(0.36-0.95)$ & $1.00(1.00-1.00)$ & - & - & - \\
\hline OPLAH & $0.60(0.36-0.85)$ & $0.60(0.21-0.99)$ & - & - & - \\
\hline PER1 & $0.65(0.31-1.00)$ & $0.64(0.25-1.00)$ & - & Yes & - \\
\hline PFN1 & $0.75(0.55-0.94)$ & $0.64(0.20-1.00)$ & Yes & - & Yes \\
\hline PPBP & $0.62(0.41-0.83)$ & $0.76(0.41-1.00)$ & - & - & - \\
\hline RAB17 & $0.61(0.28-0.94)$ & $0.64(0.25-1.00)$ & - & - & - \\
\hline S100A12 & $0.73(0.54-0.92)$ & $0.94(0.76-1.00)$ & - & - & - \\
\hline S100A8 & $0.69(0.49-0.89)$ & $0.72(0.32-1.00)$ & - & - & - \\
\hline THBS1 & $0.65(0.45-0.86)$ & $0.88(0.63-1.00)$ & Yes & Yes & - \\
\hline TLN1 & $0.74(0.56-0.92)$ & $0.60(0.19-1.00)$ & Yes & - & - \\
\hline TRRAP & $0.66(0.36-0.95)$ & $0.63(0.14-1.00)$ & - & - & - \\
\hline UNC80 & $0.65(0.42-0.89)$ & $0.81(0.43-1.00)$ & - & - & - \\
\hline USP4 & $0.60(0.38-0.81)$ & $0.94(0.76-1.00)$ & - & - & - \\
\hline VCL & $0.81(0.65-0.97)$ & $0.60(0.17-1.00)$ & Yes & - & Yes \\
\hline YWHAZ & $0.88(0.74-1.00)$ & $0.60(0.12-1.00)$ & Yes & Yes & - \\
\hline
\end{tabular}

${ }^{\dagger}$ AUC (95\% confidence interval) for distinguishing cases from matched controls. ${ }^{\ddagger}$ Proteins quantified in conditioned medium of SCLC cell lines are provided in Supplemental Dataset S2. "| ChIP Enrichment Analysis (ChEA) transcriptional targets of c-MYC and YAP1 were derived from Harmonizome database.

\subsection{Proteomic Findings in Plasmas Collected More Than One Year Prior to DIAGNOSIS}

Plasma samples were available that were collected 1-13 years prior to diagnosis. Ten cases in this group were compared to ten controls that were matched for age at the time of blood draw, smoking history and sex. We considered findings from these samples may represent potential risk markers for SCLC given the relatively long span prior to diagnosis. A total of 1242 proteins were quantified using the same criteria as for newly diagnosed cases of which 61 proteins exhibited an odds ratio (OR) of $\geq 2$ with eight proteins exhibiting a 1 -sided $p$-value $<0.05$ (Table 4). Of the proteins with an OR $\geq 2$, seven (C9, HCFC2, HYDIN, IGHM, LAMA4, RTKN and TRIM33) were also identified to be elevated (AUC $\geq 0.60$ ) in case plasmas taken at the time of diagnosis or within 0-1 years of diagnosis (Table 4 ). These proteins are associated with inflammation as in the case of LAMA4 and TRIM33 [38,39]. 
Table 4. The 61 circulating proteins that exhibited an Odds Ratio $>2$ for SCLC lung cancer.

\begin{tabular}{|c|c|c|c|c|c|}
\hline Protein & $\begin{array}{c}\text { Cases } \\
(\text { Mean } \pm \text { SD) }\end{array}$ & $\begin{array}{c}\text { Controls } \\
(\text { Mean } \pm \text { SD) }\end{array}$ & Odds Ratio $^{\dagger}$ & $\begin{array}{l}\text { 1-Sided } \\
p \text {-Value }\end{array}$ & $\begin{array}{l}\text { Elevated (AUC } \geq 0.60) \\
\text { in Case Plasmas } \ddagger\end{array}$ \\
\hline ACSL1 & $1.45 \pm 0.28$ & $1.3 \pm 0.15$ & 2.24 & 0.1000 & \\
\hline AJM1 & $1.57 \pm 0.65$ & $1.27 \pm 0.34$ & 2.01 & 0.0880 & \\
\hline AKAP9 & $2.2 \pm 0.63$ & $1.92 \pm 0.35$ & 2.02 & 0.1350 & \\
\hline ALPI & $1.26 \pm 0.09$ & $1.17 \pm 0.14$ & 2.60 & 0.0630 & \\
\hline APOD & $1.52 \pm 1.39$ & $1.05 \pm 0.22$ & 2.59 & 0.1110 & \\
\hline C4BPA & $1.28 \pm 0.17$ & $1.14 \pm 0.24$ & 2.21 & 0.0580 & \\
\hline C9 & $1.18 \pm 0.14$ & $1.05 \pm 0.22$ & 2.24 & 0.0550 & $\checkmark$ \\
\hline CARD6 & $1.38 \pm 1.29$ & $0.93 \pm 0.15$ & 2.36 & 0.1430 & \\
\hline CCDC115 & $1.12 \pm 0.14$ & $1.01 \pm 0.06$ & 9.43 & 0.0230 & \\
\hline CDHR1 & $1.93 \pm 2.24$ & $1.05 \pm 0.15$ & 25.60 & 0.0960 & \\
\hline CDKL1 & $1.09 \pm 0.1$ & $1.03 \pm 0.07$ & 2.18 & 0.0950 & \\
\hline CTNND2 & $1.16 \pm 0.29$ & $0.98 \pm 0.17$ & 2.35 & 0.0800 & \\
\hline CTPS1 & $1.57 \pm 0.83$ & $1.25 \pm 0.24$ & 2.11 & 0.1520 & \\
\hline DDX31 & $0.88 \pm 0.21$ & $0.71 \pm 0.08$ & 10.87 & 0.0110 & \\
\hline ERCC4 & $1.76 \pm 1.11$ & $1.22 \pm 0.39$ & 2.97 & 0.1000 & \\
\hline FBXL8 & $1.09 \pm 0.17$ & $0.98 \pm 0.11$ & 2.37 & 0.0430 & \\
\hline FGA & $2.07 \pm 3.5$ & $0.93 \pm 0.21$ & 4.74 & 0.1050 & \\
\hline FGB & $1.83 \pm 2.6$ & $1.02 \pm 0.2$ & 2.32 & 0.1290 & \\
\hline FGG & $2.25 \pm 3.88$ & $0.95 \pm 0.2$ & 13.01 & 0.0890 & \\
\hline FUCA1 & $1.17 \pm 0.23$ & $1.01 \pm 0.14$ & 2.85 & 0.0520 & \\
\hline HCFC2 & $1.35 \pm 0.2$ & $1.25 \pm 0.06$ & 2.72 & 0.0820 & $\checkmark$ \\
\hline HEXD & $1.83 \pm 2.23$ & $0.95 \pm 0.22$ & 4.98 & 0.1050 & \\
\hline HYDIN & $1.11 \pm 0.26$ & $0.96 \pm 0.16$ & 2.43 & 0.0850 & $\checkmark$ \\
\hline IGHM & $1.94 \pm 0.99$ & $1.39 \pm 0.41$ & 2.49 & 0.0460 & $\checkmark$ \\
\hline JMJD1C & $0.73 \pm 0.13$ & $0.65 \pm 0.1$ & 2.27 & 0.1040 & \\
\hline KIFC2 & $2.66 \pm 1.96$ & $1.74 \pm 0.45$ & 5.02 & 0.0730 & \\
\hline LAMA4 & $1.14 \pm 0.29$ & $0.97 \pm 0.2$ & 2.22 & 0.0910 & $\checkmark$ \\
\hline LENG9 & $1.41 \pm 0.16$ & $1.28 \pm 0.19$ & 2.25 & 0.0860 & \\
\hline МAP3К7 & $1.09 \pm 0.18$ & $1.01 \pm 0.04$ & 3.84 & 0.0910 & \\
\hline MAPKAPK5-AS1 & $1.11 \pm 0.5$ & $0.87 \pm 0.16$ & 2.87 & 0.0510 & \\
\hline MBD5 & $1 \pm 0.09$ & $0.93 \pm 0.08$ & 2.84 & 0.0480 & \\
\hline MOV10L1 & $1.24 \pm 0.16$ & $1.13 \pm 0.21$ & 2.03 & 0.1380 & \\
\hline MX1 & $1.23 \pm 0.09$ & $1.15 \pm 0.12$ & 2.34 & 0.0870 & \\
\hline NACA & $1.46 \pm 0.18$ & $1.35 \pm 0.2$ & 2.00 & 0.1230 & \\
\hline NLN & $1.21 \pm 0.11$ & $1.13 \pm 0.12$ & 2.27 & 0.0850 & \\
\hline NUCB2 & $1.24 \pm 0.12$ & $1.14 \pm 0.18$ & 2.16 & 0.0960 & \\
\hline OTUD6A & $0.9 \pm 0.11$ & $0.83 \pm 0.09$ & 2.31 & 0.0840 & \\
\hline PARD3 & $1.4 \pm 0.62$ & $1.14 \pm 0.22$ & 2.26 & 0.1390 & \\
\hline PCNT & $1.11 \pm 0.28$ & $0.9 \pm 0.27$ & 2.56 & 0.0640 & \\
\hline PDE4DIP & $1.74 \pm 1.12$ & $1.28 \pm 0.35$ & 2.28 & 0.1230 & \\
\hline PHC1 & $0.84 \pm 0.31$ & $0.7 \pm 0.04$ & 3.05 & 0.1110 & \\
\hline PHRF1 & $1.03 \pm 0.48$ & $0.84 \pm 0.17$ & 2.11 & 0.1320 & \\
\hline PIEZO1 & $1.34 \pm 0.24$ & $1.19 \pm 0.18$ & 2.27 & 0.1090 & \\
\hline PLEC & $1.29 \pm 0.24$ & $1.09 \pm 0.25$ & 2.85 & 0.0520 & \\
\hline PML & $1.15 \pm 0.12$ & $0.94 \pm 0.29$ & 3.36 & 0.0460 & \\
\hline POLR1B & $3.17 \pm 0.7$ & $2.74 \pm 0.62$ & 2.23 & 0.1020 & \\
\hline RBFA & $1.26 \pm 0.37$ & $1.04 \pm 0.29$ & 2.06 & 0.1060 & \\
\hline RCCD1 & $1.15 \pm 0.1$ & $1.05 \pm 0.09$ & 6.71 & 0.0220 & \\
\hline RNASE4 & $1.29 \pm 0.67$ & $1.05 \pm 0.16$ & 2.58 & 0.0970 & \\
\hline RTKN & $1.3 \pm 0.62$ & $1.07 \pm 0.09$ & 2.41 & 0.1440 & $\checkmark$ \\
\hline SLC4A10 & $1.51 \pm 0.33$ & $1.25 \pm 0.2$ & 3.75 & 0.0320 & \\
\hline SLC6A15 & $1.22 \pm 0.41$ & $1.05 \pm 0.06$ & 2.75 & 0.1200 & \\
\hline SPANXA2-OT1 & $1.78 \pm 1.47$ & $1.35 \pm 0.15$ & 2.01 & 0.1480 & \\
\hline THRAP3 & $1.17 \pm 0.19$ & $1.04 \pm 0.18$ & 2.20 & 0.0920 & \\
\hline TNKS1BP1 & $0.96 \pm 0.07$ & $0.92 \pm 0.05$ & 2.12 & 0.1120 & \\
\hline TNNI3K & $2.36 \pm 1.6$ & $1.71 \pm 0.24$ & 8.87 & 0.0500 & \\
\hline TRIM33 & $2.17 \pm 4.2$ & $0.73 \pm 0.25$ & 38.99 & 0.0720 & $\checkmark$ \\
\hline TTC6 & $1.12 \pm 0.86$ & $0.79 \pm 0.14$ & 2.65 & 0.1280 & \\
\hline VPS13C & $1.39 \pm 0.44$ & $1.21 \pm 0.13$ & 2.41 & 0.1330 & \\
\hline WDR44 & $1.48 \pm 1.59$ & $0.92 \pm 0.12$ & 2.42 & 0.1440 & \\
\hline WDR46 & $1.24 \pm 0.41$ & $0.95 \pm 0.32$ & 2.83 & 0.0570 & \\
\hline
\end{tabular}

${ }^{\dagger}$ Per unit increase. $\ddagger$ Designates that the respective protein was also found to be elevated (AUC $\left.\geq 0.60\right)$ in plasmas of newly diagnosed early stage SCLC cases or SCLC cases diagnosed within 1 year of blood draw relative to matched controls. 


\section{Discussion}

We report a comprehensive proteomic profiling of case plasmas collected at the time of diagnosis or preceding diagnosis of SCLC with the objective of identifying blood-based markers associated with disease pathogenesis. Our analyses revealed limited occurrence of increased levels of circulating neuroendocrine markers with a notable exception of NSE. However, a notable finding is the occurrence of circulating protein features centered on signatures of oncogenic MYC and YAP1 that were elevated in plasmas of cases at the time-of-diagnosis and at the pre-clinical stage of SCLC. We further report several proteins, with a predominance of inflammatory markers, that were elevated in all case data sets including pre-diagnostic plasmas collected more than one year prior to diagnosis of SCLC and that may be associated with increased risk of disease.

Prior studies have highlighted an essential role of MYC family genes the development of SCLC and in progression towards YAP1-positive states and a mesenchymal phenotype [40-42]. YAP1 drives mechanotransduction and remodeling of the cytoskeleton and ECM that occurs during EMT to potentiate cell growth, differentiation and malignant progression [33-37,43]. To this end, among the SCLC-associated biomarkers were several MYC- and YAP1-associated proteins related to EMT and cytoskeletal re-arrangement. EMT-related proteins included YWHAZ and THBS1 that were identified in SCLC cell line conditioned medium and that were elevated in plasmas of newly diagnosed SCLC cases as well as SCLC cases diagnosed within one year of blood draw. Recent evidence has identified a novel function of YWHAZ in activating $\beta$-catenin mediated transcription to promote EMT and lung cancer metastasis [44]. Similarly, THBS1 has been shown enhance EMT and promote cancer spreading $[45,46]$. Among the cytoskeletal-associated proteins that identified in conditioned medium of SCLC cell lines and that were elevated in both early stage and pre-clinical case plasmas were PFN1 and VCL, which have similarly been linked to promoting tumor progression and invasiveness [47-49].

We have previously conducted proteomic analyses of plasmas from several mouse models of lung cancer [12]. Among the proteins elevated in plasma of SCLC-bearing mice were ALDOA, CAP1, FBLN2, FGL1, GSR, KRIT1, LTBP4, PDIA3, PKP3, PSMA5, S100A8, SH3BGL3, TPM4 and YWHAE, which were also identified as elevated in case plasmas (AUC $\geq 0.60$ ) in this study, thus providing additional validation of the association between these circulating protein features and SCLC development.

It is noteworthy that several of the protein features found to be elevated in blood taken at the time of diagnosis or preceding diagnosis of SCLC are previously annotated as nuclear proteins. This may be attributed to their release from apoptotic cancer cells, membrane shedding, or occurrence in microparticles such as cancer-cell derived extracellular vesicles [50,51].

We acknowledge that our specimen sets were limited with respect to sample size. Nevertheless, our analyses identified 31 proteins that were elevated in plasmas of early stage SCLC case and that were also elevated in plasmas of SCLC cases diagnosed within one year of blood draw. Although NSE was identified to be elevated in case plasmas, other previously reported SCLC associated markers, such as ProGRP, CgA and POMC, were not detected in our specimen sets [13-19]. This may be attributed to limited expression at early stage. Alternatively, these proteins may be associated with complexes such as autoantibodies or may occur as heavily modified proteins (e.g., protein glycosylation) [52] that would limit their identification by mass spectrometry.

\section{Conclusions}

In NLST, CT-based screening was not effective for detecting early stage SCLC and no survival improvement was found amongst these individuals [7]. Data from this study revealed several novel circulating protein features that manifest in the blood of early stage SCLC cases and that are associated with oncogenic drivers of SCLC. Candidate biomarkers described herein may have clinical utility for identifying individuals that are at high-risk of developing or harboring SCLC and that would benefit from more intensive follow-up. 
Further independent validation of candidate proteins is warranted to determine their utility for earlier detection of SCLC.

Supplementary Materials: The following are available online at https:/ /www.mdpi.com/article/10 .3390/cancers13163972/s1, Dataset S1: Predictive performance of circulating proteins for distinguishing newly-diagnosed early-stage SCLC cases from matched controls, Dataset S2: Proteins quantified in conditioned medium of SCLC cell lines, Dataset S3: Predictive performance of circulating proteins for distinguishing cases diagnosed within one year of blood draw from matched controls.

Author Contributions: Conceptualization, J.F.F., H.K., E.I. and S.H.; methodology, J.F.F., H.K., E.I., E.M., L.R. and J.B.D.; validation, J.F.F., H.K., E.I. and S.H.; formal analysis, J.F.F., H.K., E.I. and X.M.; investigation, J.F.F., H.K., E.I. and J.V.; resources, H.T., D.O.W., J.-M.Y. and S.H.; data curation, J.F.F., H.K., E.I., E.M., L.R. and J.B.D.; writing — original draft preparation, J.F.F., H.K. and E.I.; writingreview and editing, J.F.F., H.K., E.I., A.C., T.K., X.M., S.P., E.M., L.R., C.-Y.Y., Y.C., F.C.H., J.B.D., H.T., E.O., D.O.W., J.-M.Y., J.V. and S.H.; visualization, J.F.F. and E.I.; supervision, S.H.; project administration, J.B.D.; funding acquisition, S.H. All authors have read and agreed to the published version of the manuscript.

Funding: This work is dedicated to the memory of Dr. Adi Gazdar our esteemed collaborator on SCLC. Work was supported by the NIH (5U01CA213285-04 and 1U01CA194733) and by the generous philanthropic contributions to The University of Texas MD Anderson Cancer Center Moon Shots Program ${ }^{\mathrm{TM}}$.

Institutional Review Board Statement: The study was conducted according to the guidelines of the Declaration of Helsinki, and approved by the Institutional Review Board at MDACC (IRB protocol \#s PA13-0589 and 2013-0609), and at the University of Pittsburgh (IRB protocol \# 011171).

Informed Consent Statement: All human blood samples were obtained following institutional review board approval, and patients provided written informed consent.

Data Availability Statement: Relevant data supporting the findings of this study are available within the Article, the Appendix A and Supplementary datafiles. Information or are available from the authors upon reasonable request.

Conflicts of Interest: The authors intend to file an intellectual property disclosure related to findings reported in the current study.

\section{Appendix A}

Table A1. Description of SCLC Cell Lines.

\begin{tabular}{cccc}
\hline \multicolumn{4}{c}{ Small-Cell Lung Cancer Cell Lines } \\
\hline Cell Line & Type & Neuroendocrine Status & Subtype $\ddagger$ \\
\hline HCC4002 & SCLC & NE & SCLC-N \\
H209 & SCLC & NE & SCLC-A \\
H2195 & SCLC & NE & SCLC-A \\
H345 & SCLC & NE & SCLC-A \\
H524 & SCLC & NE & SCLC-N \\
H69 & SCLC & NE & SCLC-A \\
HCC4001 & SCLC & NE & SCLC-A \\
HCC4003 & SCLC & NE & SCLC-N \\
HCC4004 & SCLC & NE & SCLC-N \\
HCC4005 & SCLC & Non-NE & SCLC-Y \\
H1607 & SCLC & Non-NE & SCLC-P \\
H211 & SCLC & Non-NE & SCLC-P \\
H2679 & SCLC & Non-NE & SCLC-Y \\
H526 & SCLC & Non-NE & SCLC-Y \\
H69AD & SCLC & Non-NE & SCLC-P \\
H82 & SCLC & Non-NE & \\
H1048 & SCLC &
\end{tabular}

‡ based on consensus molecular subtypes of small-cell lung cancer [24]. 
Table A2. Proteins elevated in case plasmas that are associated with MYC and EMT.

\begin{tabular}{cc}
\hline MYC-Associated Target & Reference(s) Linking to EMT \\
\hline ANKHD1 & {$[53]$} \\
ANPEP & {$[54,55]$} \\
CDH12 & {$[56]$} \\
CDH13 & {$[57]$} \\
CIT & {$[58]$} \\
CLASP2 & {$[59]$} \\
DIAPH3 & {$[60]$} \\
EGFL7 & {$[61]$} \\
FBXO11 & {$[62]$} \\
FOXP2 & {$[63]$} \\
IQGAP3 & {$[64]$} \\
PAX1 & {$[65]$} \\
PLEKHA1 & {$[66]$} \\
THBS1 & {$[45,46]$} \\
TPM1 & {$[67]$} \\
TPX2 & {$[68]$} \\
YWHAZ & {$[44]$} \\
\hline
\end{tabular}

Table A3. IPA analyses on YAP1-associated proteins that were elevated (AUC $\geq 0.60$ ) in case plasmas collected at the time of diagnosis or within one-year preceding diagnosis of SCLC.

\begin{tabular}{|c|c|c|}
\hline \multicolumn{3}{|c|}{ MDACC Early Stage SCLC Cohort } \\
\hline \multicolumn{3}{|c|}{ Top 5 Canonical Pathways } \\
\hline Pathway & $p$-Value & \# Molecules \\
\hline Actin Cytoskeleton Signaling & $4.01 \times 10^{9}$ & 9 \\
\hline Epithelial Adherens Junction Signaling & $7.30 \times 10^{8}$ & 7 \\
\hline Germ Cell-Sertoli Cell Junction Signaling & $2.38 \times 10^{6}$ & 6 \\
\hline ILK Signaling & $5.67 \times 10^{6}$ & 6 \\
\hline FAK Signaling & $7.47 \times 10^{6}$ & 5 \\
\hline \multicolumn{3}{|c|}{ SCLC Pre-Diagnostic (0-1 year] } \\
\hline \multicolumn{3}{|c|}{ Top 5 Canonical Pathways } \\
\hline Pathway & $p$-Value & \# Molecules \\
\hline Epithelial Adherens Junction Signaling & $9.10 \times 10^{5}$ & 5 \\
\hline Dilated Cardiomyopathy Signaling Pathway & $8.66 \times 10^{4}$ & 4 \\
\hline Phagosome Maturation & $9.34 \times 10^{4}$ & 4 \\
\hline Remodeling of Epithelial Adherens Junctions & $9.42 \times 10^{4}$ & 3 \\
\hline Germ Cell-Sertoli Cell Junction Signaling & $1.39 \times 10^{3}$ & 4 \\
\hline
\end{tabular}

\# number of YAP1-associated proteins in respective pathway based on IPA analysis.

Table A4. IPA analyses on the 28 proteins that were elevated (AUC $\geq 0.60$ ) in case plasmas collected at the time of diagnosis of SCLC and that were quantified in conditioned medium of SCLC cell lines.

\begin{tabular}{ccc}
\hline & Top 5 Canonical Pathways & \\
\hline Pathway & $p$-Value & \# Molecules \\
\hline Integrin Signaling & $6.97 \times 10^{6}$ & 5 \\
VEGF Signaling & $8.01 \times 10^{6}$ & 4 \\
Paxillin Signaling & $1.15 \times 10^{5}$ & 4 \\
Actin Cytoskeleton Signaling & $1.50 \times 10^{5}$ & 5 \\
FAK Signaling & $1.65 \times 10^{5}$ & 4 \\
\hline
\end{tabular}

\# number of proteins in respective pathway based on IPA analysis. 


\section{References}

1. $\quad$ Park, K.S.; Liang, M.C.; Raiser, D.M.; Zamponi, R.; Roach, R.R.; Curtis, S.J.; Walton, Z.; Schaffer, B.E.; Roake, C.M.; Zmoos, A.F.; et al. Characterization of the cell of origin for small cell lung cancer. Cell Cycle 2011, 10, 2806-2815. [CrossRef]

2. Van Meerbeeck, J.P.; Fennell, D.A.; De Ruysscher, D.K. Small-cell lung cancer. Lancet 2011, 378, 1741-1755. [CrossRef]

3. Lee, C.B.; Morris, D.E.; Fried, D.B.; Socinski, M.A. Current and evolving treatment options for limited stage small cell lung cancer. Curr. Opin. Oncol. 2006, 18, 162-172. [CrossRef]

4. Aberle, D.R.; Adams, A.M.; Berg, C.D.; Black, W.C.; Clapp, J.D.; Fagerstrom, R.M.; Gareen, I.F.; Gatsonis, C.; Marcus, P.M.; Sicks, J.D. Reduced lung-cancer mortality with low-dose computed tomographic screening. N. Engl. J. Med. 2011, 365, 395-409. [CrossRef] [PubMed]

5. $\quad$ de Koning, H.J.; van der Aalst, C.M.; de Jong, P.A.; Scholten, E.T.; Nackaerts, K.; Heuvelmans, M.A.; Lammers, J.J.; Weenink, C.; Yousaf-Khan, U.; Horeweg, N.; et al. Reduced Lung-Cancer Mortality with Volume CT Screening in a Randomized Trial. N. Engl. J. Med. 2020, 382, 503-513. [CrossRef] [PubMed]

6. Pasquinelli, M.M.; Kovitz, K.L.; Koshy, M.; Menchaca, M.G.; Liu, L.; Winn, R.; Feldman, L.E. Outcomes from a Minority-Based Lung Cancer Screening Program vs the National Lung Screening Trial. JAMA Oncol. 2018, 4, 1291-1293. [CrossRef] [PubMed]

7. Thomas, A.; Pattanayak, P.; Szabo, E.; Pinsky, P. Characteristics and Outcomes of Small Cell Lung Cancer Detected by CT Screening. Chest 2018, 154, 1284-1290. [CrossRef]

8. Guida, F.; Sun, N.; Bantis, L.E.; Muller, D.C.; Li, P.; Taguchi, A.; Dhillon, D.; Kundnani, D.L.; Patel, N.J.; Yan, Q.; et al. Assessment of Lung Cancer Risk on the Basis of a Biomarker Panel of Circulating Proteins. JAMA Oncol. 2018, 4, e182078. [CrossRef]

9. Fahrmann, J.F.; Vykoukal, J.; Fleury, A.; Tripathi, S.; Dennison, J.B.; Murage, E.; Wang, P.; Yu, C.Y.; Capello, M.; Creighton, C.J.; et al. Association between plasma diacetylspermine and tumor spermine synthase with outcome in triple negative breast cancer. J. Natl. Cancer Inst. 2019, 112, 607-616. [CrossRef]

10. Fahrmann, J.F.; Bantis, L.E.; Capello, M.; Scelo, G.; Dennison, J.B.; Patel, N.; Murage, E.; Vykoukal, J.; Kundnani, D.L.; Foretova, L.; et al. A Plasma-Derived Protein-Metabolite Multiplexed Panel for Early-Stage Pancreatic Cancer. J. Natl. Cancer Inst. 2019, 111, 372-379. [CrossRef]

11. Cohen, J.D.; Li, L.; Wang, Y.; Thoburn, C.; Afsari, B.; Danilova, L.; Douville, C.; Javed, A.A.; Wong, F.; Mattox, A.; et al. Detection and localization of surgically resectable cancers with a multi-analyte blood test. Science 2018, 359, 926-930. [CrossRef]

12. Taguchi, A.; Politi, K.; Pitteri, S.J.; Lockwood, W.W.; Faca, V.M.; Kelly-Spratt, K.; Wong, C.H.; Zhang, Q.; Chin, A.; Park, K.S.; et al. Lung cancer signatures in plasma based on proteome profiling of mouse tumor models. Cancer Cell 2011, 20, 289-299. [CrossRef] [PubMed]

13. Bork, E.; Hansen, M.; Urdal, P.; Paus, E.; Holst, J.J.; Schifter, S.; Fenger, M.; Engbaek, F. Early detection of response in small cell bronchogenic carcinoma by changes in serum concentrations of creatine kinase, neuron specific enolase, calcitonin, ACTH, serotonin and gastrin releasing peptide. Eur. J. Cancer Clin. Oncol. 1988, 24, 1033-1038. [CrossRef]

14. Molina, R.; Auge, J.M.; Escudero, J.M.; Marrades, R.; Vinolas, N.; Carcereny, E.; Ramirez, J.; Filella, X. Mucins CA 125, CA 19.9, CA 15.3 and TAG-72.3 as tumor markers in patients with lung cancer: Comparison with CYFRA 21-1, CEA, SCC and NSE. Tumour Biol. 2008, 29, 371-380. [CrossRef]

15. Pujol, J.L.; Quantin, X.; Jacot, W.; Boher, J.M.; Grenier, J.; Lamy, P.J. Neuroendocrine and cytokeratin serum markers as prognostic determinants of small cell lung cancer. Lung Cancer 2003, 39, 131-138. [CrossRef]

16. Shibayama, T.; Ueoka, H.; Nishii, K.; Kiura, K.; Tabata, M.; Miyatake, K.; Kitajima, T.; Harada, M. Complementary roles of pro-gastrin-releasing peptide (ProGRP) and neuron specific enolase (NSE) in diagnosis and prognosis of small-cell lung cancer (SCLC). Lung Cancer 2001, 32, 61-69. [CrossRef]

17. Borglum, T.; Rehfeld, J.F.; Drivsholm, L.B.; Hilsted, L. Processing-independent quantitation of chromogranin a in plasma from patients with neuroendocrine tumors and small-cell lung carcinomas. Clin. Chem. 2007, 53, 438-446. [CrossRef] [PubMed]

18. Holdenrieder, S.; von Pawel, J.; Dankelmann, E.; Duell, T.; Faderl, B.; Markus, A.; Siakavara, M.; Wagner, H.; Feldmann, K.; Hoffmann, H.; et al. Nucleosomes, ProGRP, NSE, CYFRA 21-1, and CEA in monitoring first-line chemotherapy of small cell lung cancer. Clin. Cancer Res. 2008, 14, 7813-7821. [CrossRef] [PubMed]

19. Giovanella, L.; Piantanida, R.; Ceriani, L.; Bandera, M.; Novario, R.; Bianchi, L.; Roncari, G. Immunoassay of neuron-specific enolase (NSE) and serum fragments of cytokeratin 19 (CYFRA 21.1) as tumor markers in small cell lung cancer: Clinical evaluation and biological hypothesis. Int. J. Biol. Markers 1997, 12, 22-26. [CrossRef] [PubMed]

20. Mollaoglu, G.; Guthrie, M.R.; Böhm, S.; Brägelmann, J.; Can, I.; Ballieu, P.M.; Marx, A.; George, J.; Heinen, C.; Chalishazar, M.D.; et al. MYC Drives Progression of Small Cell Lung Cancer to a Variant Neuroendocrine Subtype with Vulnerability to Aurora Kinase Inhibition. Cancer Cell 2017, 31, 270-285. [CrossRef]

21. Pedersen, N.; Mortensen, S.; Sørensen, S.B.; Pedersen, M.W.; Rieneck, K.; Bovin, L.F.; Poulsen, H.S. Transcriptional gene expression profiling of small cell lung cancer cells. Cancer Res. 2003, 63, 1943-1953. [PubMed]

22. Peifer, M.; Fernandez-Cuesta, L.; Sos, M.L.; George, J.; Seidel, D.; Kasper, L.H.; Plenker, D.; Leenders, F.; Sun, R.; Zander, T.; et al. Integrative genome analyses identify key somatic driver mutations of small-cell lung cancer. Nat. Genet. 2012, 44, 1104-1110. [CrossRef] [PubMed]

23. Umemura, S.; Mimaki, S.; Makinoshima, H.; Tada, S.; Ishii, G.; Ohmatsu, H.; Niho, S.; Yoh, K.; Matsumoto, S.; Takahashi, A.; et al. Therapeutic priority of the PI3K/AKT/mTOR pathway in small cell lung cancers as revealed by a comprehensive genomic analysis. J. Thorac. Oncol. 2014, 9, 1324-1331. [CrossRef] [PubMed] 
24. Rudin, C.M.; Poirier, J.T.; Byers, L.A.; Dive, C.; Dowlati, A.; George, J.; Heymach, J.V.; Johnson, J.E.; Lehman, J.M.; MacPherson, D.; et al. Molecular subtypes of small cell lung cancer: A synthesis of human and mouse model data. Nat. Rev. Cancer 2019, 19, 289-297. [CrossRef]

25. Wilson, D.O.; Weissfeld, J.L.; Fuhrman, C.R.; Fisher, S.N.; Balogh, P.; Landreneau, R.J.; Luketich, J.D.; Siegfried, J.M. The Pittsburgh Lung Screening Study (PLuSS): Outcomes within 3 years of a first computed tomography scan. Am. J. Respir Crit Care Med. 2008, 178, 956-961. [CrossRef]

26. Hankin, J.H.; Stram, D.O.; Arakawa, K.; Park, S.; Low, S.H.; Lee, H.P.; Yu, M.C. Singapore Chinese Health Study: Development, validation, and calibration of the quantitative food frequency questionnaire. Nutr. Cancer 2001, 39, 187-195. [CrossRef] [PubMed]

27. Ong, S.-E.; Mann, M. A practical recipe for stable isotope labeling by amino acids in cell culture (SILAC). Nat. Protoc. 2006, 1, 2650-2660. [CrossRef] [PubMed]

28. Krämer, A.; Green, J.; Pollard, J., Jr.; Tugendreich, S. Causal analysis approaches in Ingenuity Pathway Analysis. Bioinformatics 2014, 30, 523-530. [CrossRef]

29. Rouillard, A.D.; Gundersen, G.W.; Fernandez, N.F.; Wang, Z.; Monteiro, C.D.; McDermott, M.G.; Ma'ayan, A. The harmonizome: A collection of processed datasets gathered to serve and mine knowledge about genes and proteins. Database 2016, 2016, baw100. [CrossRef]

30. Lachmann, A.; Xu, H.; Krishnan, J.; Berger, S.I.; Mazloom, A.R.; Ma'ayan, A. ChEA: Transcription factor regulation inferred from integrating genome-wide ChIP-X experiments. Bioinformatics 2010, 26, 2438-2444. [CrossRef]

31. DeLong, E.R.; DeLong, D.M.; Clarke-Pearson, D.L. Comparing the areas under two or more correlated receiver operating characteristic curves: A nonparametric approach. Biometrics 1988, 44, 837-845. [CrossRef]

32. Pobbati, A.V.; Hong, W. Emerging roles of TEAD transcription factors and its coactivators in cancers. Cancer Biol. Ther. 2013, 14, 390-398. [CrossRef]

33. Dupont, S.; Morsut, L.; Aragona, M.; Enzo, E.; Giulitti, S.; Cordenonsi, M.; Zanconato, F.; Le Digabel, J.; Forcato, M.; Bicciato, S.; et al. Role of YAP/TAZ in mechanotransduction. Nature 2011, 474, 179-183. [CrossRef]

34. Zhang, J.; Zhou, Y.; Tang, P.M.K.; Cheng, A.S.L.; Yu, J.; To, K.F.; Kang, W. Mechanotransduction and Cytoskeleton Remodeling Shaping YAP1 in Gastric Tumorigenesis. Int. J. Mol. Sci. 2019, 20, 1576. [CrossRef] [PubMed]

35. Aseervatham, J. Cytoskeletal Remodeling in Cancer. Biology 2020, 9, 385. [CrossRef]

36. Walker, C.; Mojares, E.; Del Río Hernández, A. Role of Extracellular Matrix in Development and Cancer Progression. Int. J. Mol. Sci. 2018, 19, 3028. [CrossRef]

37. Lambert, A.W.; Weinberg, R.A. Linking EMT programmes to normal and neoplastic epithelial stem cells. Nat. Rev. Cancer 2021, 21, 325-338. [CrossRef]

38. Tanaka, S.; Jiang, Y.; Martinez, G.J.; Tanaka, K.; Yan, X.; Kurosaki, T.; Kaartinen, V.; Feng, X.H.; Tian, Q.; Wang, X.; et al. Trim33 mediates the proinflammatory function of Th17 cells. J. Exp. Med. 2018, 215, 1853-1868. [CrossRef] [PubMed]

39. Prabhala, P.; Wright, D.B.; Robbe, P.; Bitter, C.; Pera, T.; Ten Hacken, N.H.T.; van den Berge, M.; Timens, W.; Meurs, H.; Dekkers, B.G.J. Laminin $\alpha 4$ contributes to airway remodeling and inflammation in asthma. Am. J. Physiol. Lung Cell Mol. Physiol. 2019, 317, L768-L777. [CrossRef] [PubMed]

40. Ireland, A.S.; Micinski, A.M.; Kastner, D.W.; Guo, B.; Wait, S.J.; Spainhower, K.B.; Conley, C.C.; Chen, O.S.; Guthrie, M.R.; Soltero, D.; et al. MYC Drives Temporal Evolution of Small Cell Lung Cancer Subtypes by Reprogramming Neuroendocrine Fate. Cancer Cell 2020, 38, 60-78. [CrossRef]

41. Patel, A.S.; Yoo, S.; Kong, R.; Sato, T.; Sinha, A.; Karam, S.; Bao, L.; Fridrikh, M.; Emoto, K.; Nudelman, G.; et al. Prototypical oncogene family Myc defines unappreciated distinct lineage states of small cell lung cancer. Sci. Adv. 2021, 7, eabc2578. [CrossRef] [PubMed]

42. Zhang, W.; Girard, L.; Zhang, Y.A.; Haruki, T.; Papari-Zareei, M.; Stastny, V.; Ghayee, H.K.; Pacak, K.; Oliver, T.G.; Minna, J.D.; et al. Small cell lung cancer tumors and preclinical models display heterogeneity of neuroendocrine phenotypes. Transl. Lung Cancer Res. 2018, 7, 32-49. [CrossRef]

43. Calvo, F.; Ege, N.; Grande-Garcia, A.; Hooper, S.; Jenkins, R.P.; Chaudhry, S.I.; Harrington, K.; Williamson, P.; Moeendarbary, E.; Charras, G.; et al. Mechanotransduction and YAP-dependent matrix remodelling is required for the generation and maintenance of cancer-associated fibroblasts. Nat. Cell Biol. 2013, 15, 637-646. [CrossRef] [PubMed]

44. Chen, C.H.; Chuang, S.M.; Yang, M.F.; Liao, J.W.; Yu, S.L.; Chen, J.J. A novel function of YWHAZ/ $\beta$-catenin axis in promoting epithelial-mesenchymal transition and lung cancer metastasis. Mol. Cancer Res. 2012, 10, 1319-1331. [CrossRef] [PubMed]

45. Jayachandran, A.; Anaka, M.; Prithviraj, P.; Hudson, C.; McKeown, S.J.; Lo, P.H.; Vella, L.J.; Goding, C.R.; Cebon, J.; Behren, A. Thrombospondin 1 promotes an aggressive phenotype through epithelial-to-mesenchymal transition in human melanoma. Oncotarget 2014, 5, 5782-5797. [CrossRef] [PubMed]

46. Liu, X.; Xu, D.; Liu, Z.; Li, Y.; Zhang, C.; Gong, Y.; Jiang, Y.; Xing, B. THBS1 facilitates colorectal liver metastasis through enhancing epithelial-mesenchymal transition. Clin. Transl. Oncol. 2020, 22, 1730-1740. [CrossRef] [PubMed]

47. Allen, A.; Gau, D.; Francoeur, P.; Sturm, J.; Wang, Y.; Martin, R.; Maranchie, J.; Duensing, A.; Kaczorowski, A.; Duensing, S.; et al. Actin-binding protein profilin1 promotes aggressiveness of clear-cell renal cell carcinoma cells. J. Biol. Chem. 2020, 295, 15636-15649. [CrossRef] 
48. de Semir, D.; Bezrookove, V.; Nosrati, M.; Scanlon, K.R.; Singer, E.; Judkins, J.; Rieken, C.; Wu, C.; Shen, J.; Schmudermayer, C.; et al. PHIP drives glioblastoma motility and invasion by regulating the focal adhesion complex. Proc. Natl. Acad. Sci. USA 2020, 117, 9064-9073. [CrossRef] [PubMed]

49. Zheng, X.; Xu, H.; Gong, L.; Cao, D.; Jin, T.; Wang, Y.; Pi, J.; Yang, Y.; Yi, X.; Liao, D.; et al. Vinculin orchestrates prostate cancer progression by regulating tumor cell invasion, migration, and proliferation. Prostate 2021, 81, 347-356. [CrossRef]

50. Vykoukal, J.; Sun, N.; Aguilar-Bonavides, C.; Katayama, H.; Tanaka, I.; Fahrmann, J.F.; Capello, M.; Fujimoto, J.; Aguilar, M.; Wistuba, I.I.; et al. Plasma-derived extracellular vesicle proteins as a source of biomarkers for lung adenocarcinoma. Oncotarget 2017, 8, 95466-95480. [CrossRef]

51. Fahrmann, J.F.; Mao, X.; Irajizad, E.; Katayama, H.; Capello, M.; Tanaka, I.; Kato, T.; Wistuba, I.I.; Maitra, A.; Ostrin, E.J.; et al. Plasma-Derived Extracellular Vesicles Convey Protein Signatures that Reflect Pathophysiology in Lung and Pancreatic Adenocarcinomas. Cancers 2020, 12, 1147. [CrossRef]

52. Ottesen, A.H.; Christensen, G.; Omland, T.; Røsjø, H. Glycosylated Chromogranin A: Potential Role in the Pathogenesis of Heart Failure. Curr. Heart Fail. Rep. 2017, 14, 478-488. [CrossRef] [PubMed]

53. Yao, P.; Li, Y.; Shen, W.; Xu, X.; Zhu, W.; Yang, X.; Cao, J.; Xing, C. ANKHD1 silencing suppresses the proliferation, migration and invasion of CRC cells by inhibiting YAP1-induced activation of EMT. Am. J. Cancer Res. 2018, 8, 2311-2324.

54. Kim, Y.; Han, D.; Min, H.; Jin, J.; Yi, E.C.; Kim, Y. Comparative proteomic profiling of pancreatic ductal adenocarcinoma cell lines. Mol. Cells 2014, 37, 888-898. [CrossRef] [PubMed]

55. Vergara, D.; Simeone, P.; Franck, J.; Trerotola, M.; Giudetti, A.; Capobianco, L.; Tinelli, A.; Bellomo, C.; Fournier, I.; Gaballo, A.; et al. Translating epithelial mesenchymal transition markers into the clinic: Novel insights from proteomics. EuPA Open Proteom. 2016, 10, 31-41. [CrossRef]

56. Ma, J.; Zhao, J.; Lu, J.; Wang, P.; Feng, H.; Zong, Y.; Ou, B.; Zheng, M.; Lu, A. Cadherin-12 enhances proliferation in colorectal cancer cells and increases progression by promoting EMT. Tumor Biol. 2016, 37, 9077-9088. [CrossRef] [PubMed]

57. Xu, D.; Yuan, H.; Meng, Z.; Yang, C.; Li, Z.; Li, M.; Zhang, Z.; Gan, Y.; Tu, H. Cadherin 13 Inhibits Pancreatic Cancer Progression and Epithelial-mesenchymal Transition by Wnt/ $\beta$-Catenin Signaling. J. Cancer 2020, 11, 2101-2112. [CrossRef]

58. Haiping, C.; Qi, X.; Dawei, L.; Qiang, W. Citron Rho-interacting serine/threonine kinase knockdown suppresses prostate cancer cell proliferation and metastasis by blocking Hippo-YAP pathway. Nan Fang Yi Ke Da Xue Xue Bao 2019, 39, 257-263. [CrossRef]

59. Zhu, B.; Qi, L.; Liu, S.; Liu, W.; Ou, Z.; Chen, M.; Liu, L.; Zu, X.; Wang, J.; Li, Y. CLASP2 is involved in the EMT and early progression after transurethral resection of the bladder tumor. BMC Cancer 2017, 17, 105. [CrossRef] [PubMed]

60. Morley, S.; You, S.; Pollan, S.; Choi, J.; Zhou, B.; Hager, M.H.; Steadman, K.; Spinelli, C.; Rajendran, K.; Gertych, A.; et al. Regulation of microtubule dynamics by DIAPH3 influences amoeboid tumor cell mechanics and sensitivity to taxanes. Sci. Rep. 2015, 5, 12136. [CrossRef]

61. Luo, B.H.; Xiong, F.; Wang, J.P.; Li, J.H.; Zhong, M.; Liu, Q.L.; Luo, G.Q.; Yang, X.J.; Xiao, N.; Xie, B.; et al. Epidermal growth factor-like domain-containing protein 7 (EGFL7) enhances EGF receptor-AKT signaling, epithelial-mesenchymal transition, and metastasis of gastric cancer cells. PLoS ONE 2014, 9, e99922. [CrossRef] [PubMed]

62. Song, Y.; Lin, M.; Liu, Y.; Wang, Z.-W.; Zhu, X. Emerging role of F-box proteins in the regulation of epithelial-mesenchymal transition and stem cells in human cancers. Stem Cell Res. Ther. 2019, 10, 124. [CrossRef] [PubMed]

63. Liu, Y.; Chen, T.; Guo, M.; Li, Y.; Zhang, Q.; Tan, G.; Yu, L.; Tan, Y. FOXA2-Interacting FOXP2 Prevents Epithelial-Mesenchymal Transition of Breast Cancer Cells by Stimulating E-Cadherin and PHF2 Transcription. Front. Oncol. 2021, 11, 605025. [CrossRef] [PubMed]

64. Shi, Y.; Qin, N.; Zhou, Q.; Chen, Y.; Huang, S.; Chen, B.; Shen, G.; Jia, H. Role of IQGAP3 in metastasis and epithelial-mesenchymal transition in human hepatocellular carcinoma. J. Transl. Med. 2017, 15, 176. [CrossRef]

65. Siletz, A.; Schnabel, M.; Kniazeva, E.; Schumacher, A.J.; Shin, S.; Jeruss, J.S.; Shea, L.D. Dynamic transcription factor networks in epithelial-mesenchymal transition in breast cancer models. PLoS ONE 2013, 8, e57180. [CrossRef]

66. Shapiro, I.M.; Cheng, A.W.; Flytzanis, N.C.; Balsamo, M.; Condeelis, J.S.; Oktay, M.H.; Burge, C.B.; Gertler, F.B. An EMT-driven alternative splicing program occurs in human breast cancer and modulates cellular phenotype. PLoS Genet. 2011, 7, e1002218. [CrossRef] [PubMed]

67. Kubo, E.; Hasanova, N.; Fatma, N.; Sasaki, H.; Singh, D.P. Elevated tropomyosin expression is associated with epithelialmesenchymal transition of lens epithelial cells. J. Cell Mol. Med. 2013, 17, 212-221. [CrossRef] [PubMed]

68. Zou, Z.; Zheng, B.; Li, J.; Lv, X.; Zhang, H.; Yu, F.; Kong, L.; Li, Y.; Yu, M.; Fang, L.; et al. TPX2 level correlates with cholangiocarcinoma cell proliferation, apoptosis, and EMT. Biomed. Pharmacother. 2018, 107, 1286-1293. [CrossRef] [PubMed] 